Western University

Scholarship@Western

Communication Sciences and Disorders

Publications

Communication Sciences and Disorders School

$1-1-2019$

\title{
Auditory brainstem responses in children with auditory processing disorder
}

Sangamanatha Ankmnal-Veeranna

The University of Western Ontario

Chris Allan

The University of Western Ontario

Prudence Allen

The University of Western Ontario, pallen@uwo.ca

Follow this and additional works at: https://ir.lib.uwo.ca/scsdpub

Part of the Communication Sciences and Disorders Commons

Citation of this paper:

Ankmnal-Veeranna S, Allan C, Allen P. Auditory Brainstem Responses in Children with Auditory Processing Disorder. J Am Acad Audiol. 2019 Nov/Dec;30(10):904-917. doi: 10.3766/jaaa.18046. Epub 2019 Jun 24. PMID: 31241448. 


\title{
Auditory Brainstem Responses in Children with Auditory Processing Disorder
}

DOI: $10.3766 /$ jaaa. 18046

\author{
Sangamanatha Ankmnal-Veeranna* \\ Chris Allan*ं \\ Prudence Allen*†
}

\begin{abstract}
Background: The ASHA recommends including electrophysiological measures in an auditory processing disorder (APD) assessment battery, but few audiologists do so, potentially because of limited published evidence for its utility.
\end{abstract}

Purpose: This study compared the auditory brainstem responses (ABRs) of children with APD with agematched children and adults.

Study Sample: This study retrospectively examined the records of 108 children suspected of APD (SAPD) who had click-evoked ABRs recorded as part of their clinical assessment. Twenty adults and 22 typically developing (TD) children were recruited as controls.

Data collection and Analysis: Click-evoked ABRs were recorded at slow (13.3 clicks/sec) and faster (57.7 clicks/sec) stimulation rates. ABRs were analyzed using typical clinical measures (latencies and interpeak intervals for waves I, III, and V) and using a model proposed by Ponton et al that offered a more detailed analysis of axonal conduction time and synaptic transmission delay.

Results: Both clinical measures and the Ponton model analysis showed no significant differences between TD children and adults. Children SAPD showed absolute latencies that were significantly prolonged when compared with adults but not when compared with TD children. But individual children SAPD showed clinically significant delays ( $>2$ standard deviations of TD children's data). Examination of responses delineating axonal versus synaptic transmission showed significant delays in synaptic transmission in the group of children SAPD in comparison to TD children and adults. These results suggest that a significant portion of children with listening difficulties showed evidence of reduced or atypical brainstem functioning. Examining the responses for axonal and synaptic delays revealed evidence of a synaptic pattern of abnormalities in a significant portion (37.03\%) of children SAPD. Such observations could provide objective evidence of factors potentially contributing to listening difficulties that are frequently reported in children identified with APD.

Conclusions: Children sAPD often showed abnormalities in the ABR, suggesting a neurophysiologic origin of their reported difficulties, frequently originating at or before the first synapse. This study provides supportive evidence for the value of click-evoked ABRs in comprehensive auditory processing assessment batteries.

Key Words: auditory processing disorder, axonal conduction time, click-evoked ABR, synaptic transmission time

Abbreviations: $\mathrm{ABR}=$ auditory brainstem responses; $\mathrm{APD}=$ auditory processing disorder; $\mathrm{CA}=$ conceptual age; CNC = cochlear nucleus complex; RMANOVA = repeated measure analysis of variance; SAPD = suspected of APD; SD = standard deviation; TD = typically developing

*National Centre for Audiology, Western University, London, Canada; $†$ School of Communication Science and Disorder, Western University, London, Canada

Corresponding author: Prudence Allen, National Centre for Audiology, Elborn College, London, Canada N6G1H1; Email: pallen@uwo.ca

This paper was presented at the Canadian Academy of Audiology Conference, Ottawa, 2017. 


\section{INTRODUCTION}

$\mathrm{S}$ chool-aged children are often referred to audiology for assessment because of concern about their hearing in difficult listening situations. These children, when found to have normal hearing threshold levels, may be suspected of having an auditory processing disorder (APD). APD is heterogenous in nature. The diagnosis of APD is challenging because there is no one diagnostic procedure that is agreed on by hearing health-care professionals, potentially leading to inconsistent identification (Hind, 2006). Professional guidelines (ASHA, 2005; AAA, 2010) typically recommend behavioral test batteries consisting of speech and nonspeech tests designed to examine auditory skills. An assessment battery can include tests of auditory discrimination, temporal processing, auditory pattern recognition, binaural interaction, and the perception of monaural low redundancy and dichotic speech (ASHA, 2005). A diagnosis of APD is made based on the overall performance on the test battery. Although the manner in which test results are combined may vary, typically performance deficits in at least two or more tests in the battery falling at least 2 standard deviations (SDs) below age expectations are used to support an APD diagnosis (Chermak and Musiek, 1997). If only one test is administered, the child would be identified as APD only if performance was at least 3 SDs below expectations (ASHA, 2005).

The use of behavioral measures in diagnosing children with APD is controversial. Speech tests (word or sentence repetition) have linguistic information, making it difficult to distinguish between listening and language skills (Hall, 2007). Behavioral test results may also be affected by attention (Sharma et al, 2009).

Professional guidelines often recommend the inclusion of objective/physiological measures to assess the integrity of the auditory nervous system for APD. Using neurophysiologic techniques may provide some assistance in avoiding language and attentional confounds (Dawes and Bishop, 2009). However, very few clinicians include objective measures in their test battery. A survey of audiologists on protocols used to assess APD revealed that $<15 \%$ of clinicians indicated using electrophysiology tools such as the auditory brainstem response $(\mathrm{ABR})$, middle latency response, or cortical evoked potentials as part of their standard central auditory battery (Emanuel et al, 2011). AAA (2010) described the value of click-evoked $A B R$ as limited and some authors have criticized the inclusion of the ABR in a routine diagnostic battery because of lack of evidence (Katz et al, 2000). This is unfortunate because the ABR has the potential to provide useful information regarding the integrity of the ascending auditory pathway.
The ABR is widely used for objective hearing threshold and neurodiagnostic assessment (Starr and Achor, 1975; Stapells and Oates, 1997). It is a robust response characterized by low intra-subject variability in both amplitude and latency (Lauter and Loomis, 1986). The time at which peaks are generated provides information regarding travel time in the brainstem. A delay in absolute or interwave intervals may suggest impairment, as may the inability of the system to maintain integrity with increasing stimulation rates. The $\mathrm{ABR}$ has been used as an objective tool to study auditory neural integrity in children suspected of APD (sAPD) (Gopal and Kowalski, 1999; Jirsa, 2001; Allen and Allan, 2014), although the number of reported studies is limited and patient populations are often small. For example, Gopal and Kowalski (1999) recorded ABRs in nine children with APD and nine typically developing (TD) children. They used slope vector analysis, which calculates the amplitude difference between a positive peak and the following negative peak divided by the travel time. The slope decreases when the amplitude of the peaks is low or the travel time is lengthened. Children with APD demonstrated lower slopes than age-matched controls. The effect of the stimulus repetition rate was studied by Jirsa (2001) who recorded maximum length sequence ABRs in 37 children diagnosed with APD and age-matched controls. They found wave V latency was significantly delayed in children with APD when the stimuli were presented at a very high rate $(909.1 / \mathrm{sec})$. Allen and Allan (2014) recorded ABRs for slow (21.7-27.7/sec) and faster rates $(57.7 / \mathrm{sec})$ in 62 children with suspected APD and eight normal hearing adults. Approximately $25 \%$ of the children showed delayed wave $\mathrm{V}$ latencies at the slower stimulation rate, with many showing large rate-dependent delays.

Maturation must be considered when using the ABR as a neurodiagnostic tool for infants and very young children, but responses are thought to be mature by school age when most APD testing is recommended. The ABR can be recorded at as early as 27 weeks of conceptual age (CA), but responses are characterized by prolonged absolute and interpeak latencies and lower amplitudes when compared with those of older children and adults (Hecox and Galambos, 1974). Peak I matures rapidly, expected to be seen at adult latencies by two to three months of age, whereas peaks III and V do not mature until one to two years of age (Salamy, 1984; Gorga et al, 1989; Hall, 2006). Peaks II and IV, seldom evaluated in clinical settings, are found to follow behind the maturation of peaks I and V, respectively (Salamy, 1984). Centrally occurring waves have a longer developmental trajectory in comparison to peripherally occurring waves and this is reflected in young children as delays in interpeak intervals and increased transmission time through the brainstem. 
Changes in ABR wave amplitudes can act as an index of maturation of the auditory brainstem. V/I amplitude ratios are $>1.0$ in normal hearing adults (Starr and Achor, 1975) but are typically $<1$ until three to four years of age, after which there is an increase in peak $\mathrm{V}$ amplitude, resulting in an increased V/I ratio (Mochizuki et al, 1982; Jiang et al, 1993). Maturational changes in the ABR likely arise from increased axonal myelination and synaptic maturation (Eggermont and Salamy, 1988; Ponton et al, 1996). Understanding how axonal and synaptic factors are impacted by maturation and pathologic processes could prove useful when assessing auditory neural integrity in clinically referred children.

Ponton et al (1996) developed a model of ABR generation and maturation that attempts to isolate agerelated changes in axonal conduction and synaptic transmission. The model was derived from an extensive review of the literature, anatomical and electrophysiological data from infants and adults, intra-surgical recordings, and direct recording of the human cochlear nucleus complex (CNC) through a brainstem implant device. The model argues that peak I is generated as the auditory nerve fires from within the internal auditory canal and wave II is generated as the auditory nerve exits the internal auditory canal. The I-II inter$\mathrm{val}$ is therefore largely determined by axonal conduction and is adult-like even for premature infants, 29-34 weeks CA. Peak III is assumed to be generated by axons emerging from the $\mathrm{CNC}$ in the ventral acoustic stria and the II-III interval is therefore dominated by synaptic contributions. It does not become adult-like until 18 months post-term. Peaks IV and V are generated from the rostral brainstem location (medial olivary nucleus). The III-IV interval is axonal and attains adult levels by 40 weeks CA. By contrast, the IV-V interval, reflecting synaptic responses in the medial olivary nucleus, does not become adult-like until 11-12 months post-term. The nonlinear best-fit functions to the synaptically dominated II-III and IV-V intervals are parallel and slower than the axonally dominated I-II and III-IV intervals. This closely matches the findings of Mochizuki et al (1982), showing little change in I-II and III-IV (axonal) intervals from infancy to adulthood but significant changes in the maturation of II-III and IV-V (synaptic) intervals.

In this study, ABRs elicited both at slow (13.3 clicks/ sec) and faster stimulation rates ( 57.7 clicks/sec) were recorded from children referred for APD assessment and were retrospectively analyzed using traditional clinical measures (absolute and interwave intervals for waves I, III, and V, and the effect of stimulus presentation rate on wave $\mathrm{V}$ latency) and using Ponton et al's model to separate axonal (I-II and III-IV) and synaptic (II-III and IV-V) factors. Data from children who had been referred for APD evaluation were compared with data collected from normal hearing
TD children and adults. The goal was to determine if the more detailed analysis could provide useful clinical insights not visible with traditional, clinical inspection of the data.

\section{MATERIALS AND METHODS}

\section{Participants}

Participants included 22 children with no reported hearing or developmental concerns (4.11-16.1 years, mean $=10.71, \mathrm{SD}=3.40$ years), 20 normal hearing adults (20-35 years, mean $=23.71, \mathrm{SD}=3.90$ years), and 108 children $(5.25-15.7$ years, mean $=9.63$, $\mathrm{SD}=2.70$ years) $\mathrm{sAPD}$ referred to our clinic by physicians, community audiologists, parents, and family friends because of concerns about hearing/listening in noisy conditions as a contributor to poor academic performance. Behavioral checklists for auditory processing problems and educational risk (Children Auditory Performance Scale [Smoski et al, 1998] and Screening Identification for Targeting Educational Risk [Anderson, 1989]) indicated that these children have listening difficulties and should undergo a central auditory processing assessment. For sAPD children and TD children, air conduction hearing thresholds were obtained at octave frequencies $(250-8000 \mathrm{~Hz})$ using the Hughson-Westlake procedure (Carhart and Jerger, 1959). Air conduction threshold screening was carried out for adults to ensure that the thresholds were within $20 \mathrm{~dB}$ HL. Tympanometry was conducted with all participants to verify normal middle ear function. Distortion product otoacoustic emissions were recorded to ensure normal functioning of outer hair cells. The TD children and adult participants had no reports of listening difficulties. The Health Sciences Research Ethics Board of Western University, Canada, approved the study methods.

\section{Equipment and Stimuli}

For all participants, ABRs were acquired using a Biologic Navigator Pro AEP system (Natus Medical, Inc., Pleasanton, CA). A $100-\mu \mathrm{s}$ rarefaction click was presented at 13.3 (slow) and 57.7 (fast) clicks/sec. Stimuli were presented monaurally via insert earphones (ER3A; Etymotic Research, Inc., Elk Grove Village, IL) to the right and left ears at $80 \mathrm{dBnHL}$. Recordings were made with four surface electrodes placed at $\mathrm{Cz}$ and $\mathrm{Fz}$ (ground) positions and referenced to the right and left earlobes. Electrode impedance was less than $5 \mathrm{k} \Omega$. The responses were averaged over a $10-$ msec window, amplified (100k), and filtered (100-1500 Hz). Artifact rejection was set at $23.8 \mu \mathrm{V}$. Click responses to 2,000 repetitions were averaged for each response with a minimum of two replications. Lights in the testing room were turned off during recording to minimize electric interferences and encourage participants to rest quietly. 


\section{ABR Analysis}

Waves I to V were identified by an experienced audiologist and verified by a second experienced audiologist. Wave $\mathrm{V}$ was always marked on the prominent "shoulder" following the peak (expected to be between 5 and $6 \mathrm{msec}$ ). Interwave intervals and the effect of the stimulation rate on wave $\mathrm{V}$ were calculated. The $\mathrm{ABR}$ data were compared with measures obtained from the TD children and evaluated clinically and according to the model proposed by Ponton et al (1996). A repeated measure analysis of variance (RMANOVA) was used to evaluate group differences and effect sizes are report-

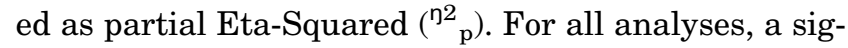
nificance level of $p<0.05$ was chosen. The analysis was conducted in SPSS (SPSS Inc., Chicago, IL). Bonferroni corrections were used to adjust for multiple comparisons in post hoc analyses. Last, because in clinical practice it is important to analyze data from individuals, not just group trends, any individual absolute and interwave latencies that were prolonged and fell $>2$ SD of TD children's data were classified as clinically abnormal (ASHA, 2005).

\section{RESULTS}

\section{Clinical Measures}

\section{Hearing Thresholds}

Figure 1 shows the mean air conduction hearing thresholds of TD children and children SAPD for the right and left ear. Adult data were not included as thresholds were screened $(<20 \mathrm{~dB}$ HL). Five sAPD children were missing air conduction thresholds at $250 \mathrm{~Hz}$, and two sAPD children had a 30-dB HL threshold (one sAPD at $250 \mathrm{~Hz}$ and another sAPD at $8000 \mathrm{~Hz}$ ). Mean air conduction thresholds of children SAPD were elevated compared with those of TD children. A RMANOVA was carried out with the ear (right and left) and frequency (250, 500,1000, 2000, 4000, and 8000) as within-subject factors and subject group (sAPD children and TD children) as the between-subject factor. TD children demonstrated significantly lower hearing thresholds than sAPD children $\left[F_{(1,123)}=9.21, p=\right.$ $\left.0.003,{ }^{n 2} \mathrm{p}=0.07\right]$. There were no significant differences in hearing thresholds between ears $\left[F_{(1,123)}=1.11, p=\right.$ $\left.0.29,{ }^{12} \mathrm{p}=0.009\right]$, and other interactions were not significant $(p>0.05)$.

\section{Absolute Latencies}

Figure 2A shows individual absolute wave I, III, and $\mathrm{V}$ latencies for TD children, sAPD children, and adults plotted as a function of age to facilitate visualization of individual data. Figure $2 \mathrm{~B}$ shows the mean $\mathrm{ABR}$ wave I, III, and V latencies as a function of groups for right and left ears. As can be seen in Figure 2A, there was no apparent age effect in the TD and SAPD children's data. A RMANOVA was carried out with ear (right and left) and absolute wave latencies (I, III, and V) as within-subject factors and subject group (sAPD children, TD children, and adults) as a between-subject factor. There was a significant difference between groups $\left[F_{(2,147)}=9.89, p<\right.$ $\left.0.0001,{ }^{\mathrm{\eta} 2} \mathrm{p}=0.119\right]$, and the wave by group interaction was significant $\left[F_{(3.46,254.71)}=2.90, p=0.028,{ }^{n 2}{ }_{p}=\right.$ $0.038]$. Bonferroni post hoc $t$-tests (adjusted) were used to examine this interaction. For wave I, the latency data from the children sAPD were significantly prolonged when compared with those from TD children $\left[t_{(147)}=\right.$ $2.62, p=0.027]$. Other group comparisons for wave I were not significant [TD children versus adults, $t_{(147)}=-0.50, p=1.000$; and children sAPD, $t_{(147)}=$ $1.89, p=0.185]$. The wave III [ $t_{(147)}=3.12, p=0.005$ ] and $\mathrm{V}\left[t_{(147)}=4.02, p<0.001\right]$ latencies were significantly prolonged in children sAPD when compared with adults. Other group comparisons were not significant \{wave III: TD children and adults $\left[t_{(147)}=1.26, p=\right.$ $0.618]$, TD children and children $\operatorname{sAPD}\left[t_{(147)}=1.62\right.$, $p=0.319]$; wave $\mathrm{V}$ : TD children and adults $\left[t_{(147)}=\right.$ 1.62, $p=0.321]$, TD children and children sAPD $\left.\left[t_{(147)}=2.04, p=0.127\right]\right\}$. There were no significant differences between ears $\left[F_{(1,147)}=1.047, p=0.308,{ }^{n 2}{ }_{\mathrm{p}}=\right.$ 0.07].

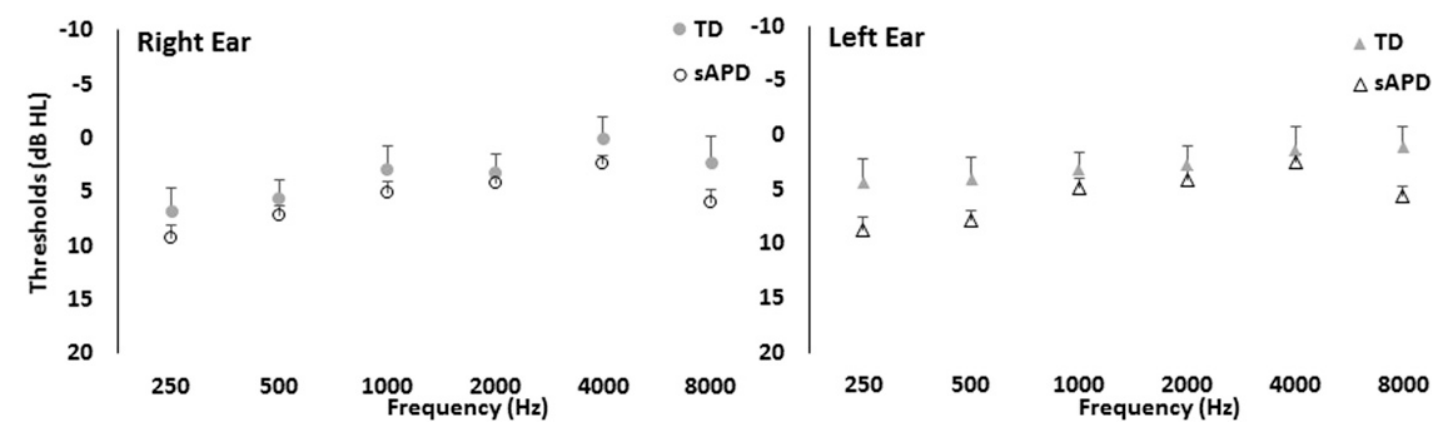

Figure 1. Air conduction hearing thresholds of TD children and children sAPD for the right and left ears as a function of frequency. Error bars around the mean represent $95 \%$ confidence intervals. 
A

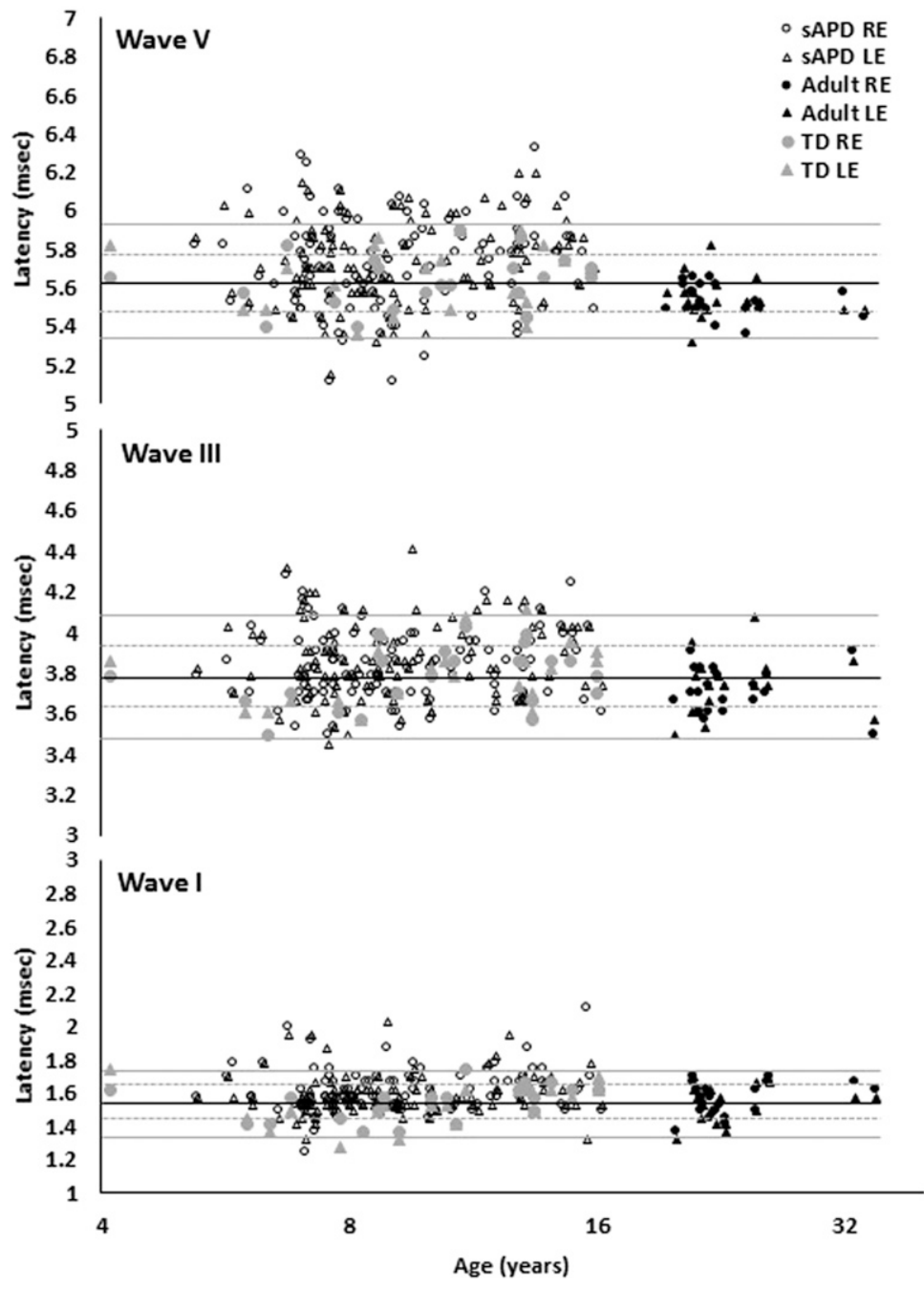

B

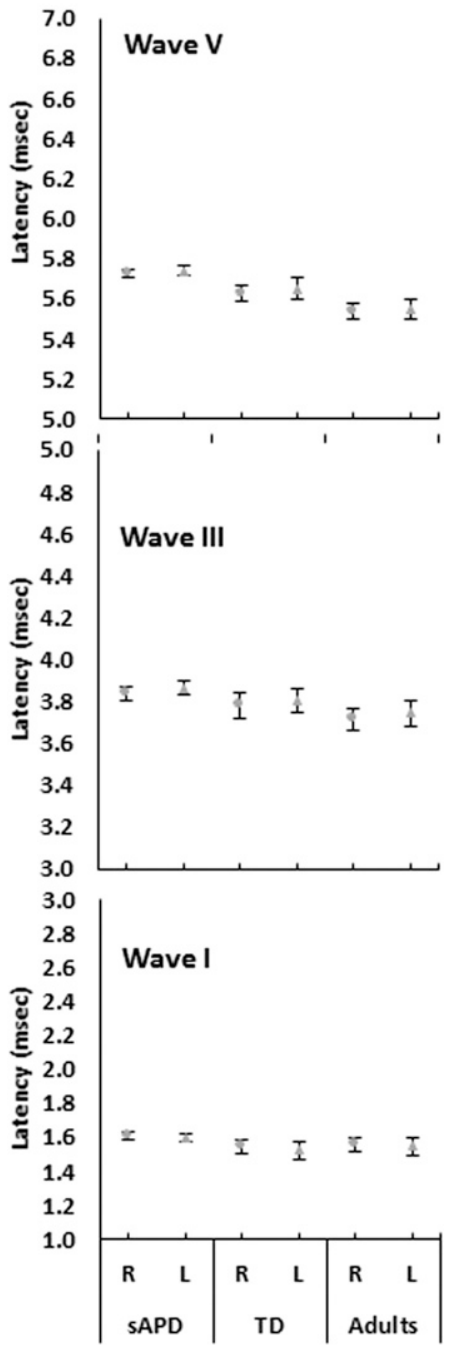

Figure 2. (A) ABR wave I, III, and V latencies plotted as a function of age for slow rates (13.3 clicks/sec). Data for TD children are shown as filled circles and filled triangles (in gray) for the right and left ears, respectively. The sAPD children responses are shown by the unfilled circles and triangles for the right and left ears, respectively. Adult responses are shown as filled circles and filled triangles (in black) for the right and left ears, respectively. The filled horizontal black line, and unfilled and filled gray lines represent TD children's mean latency value, \pm 1 and $\pm 2 \mathrm{SD}$, respectively. (B) Mean ABR wave I, III, and V latencies are plotted as a function of group for the right and left ears. Data for the right and left ears are shown as filled circles and triangles, respectively. Error bars around the mean represent $95 \%$ confidence intervals.

As can be seen in Figure 2B, the mean latencies for sAPD children were higher than those for the controls, and several individual children SAPD showed wave latencies that were clinically significant $(>2$ SD beyond expectations from the TD children's data) for waves I, III, and V. At these slower stimulation rates, 48 of the $108(44.44 \%)$ children had clinically abnormal ( $>2$ SD of TD children data) absolute latencies (either in one or more of waves I, III, and V). Of these children, $28(25.92 \%)$ children were unilateral and $20(18.51 \%)$ were bilateral. Chi-square test (two-tailed) revealed that the incidence of clinically abnormal absolute latencies was significantly different in children sAPD when compared with TD children $\left[\chi^{2}(1)=9.65\right.$, $p=0.002]$.

\section{Interwave Intervals}

Figure 3A shows I-III and III-V interwave intervals in the lower and upper panels, respectively, plotted as a function of age. Figure 3B shows mean I-III and III-V interwave interval latencies as a function of groups for right and left ears. A RMANOVA was carried out with ear (right and left) and interwave intervals (I-III and III-V) as within-subject factors and subject groups (TD children, sAPD children, and adults) as a between-subject 
A

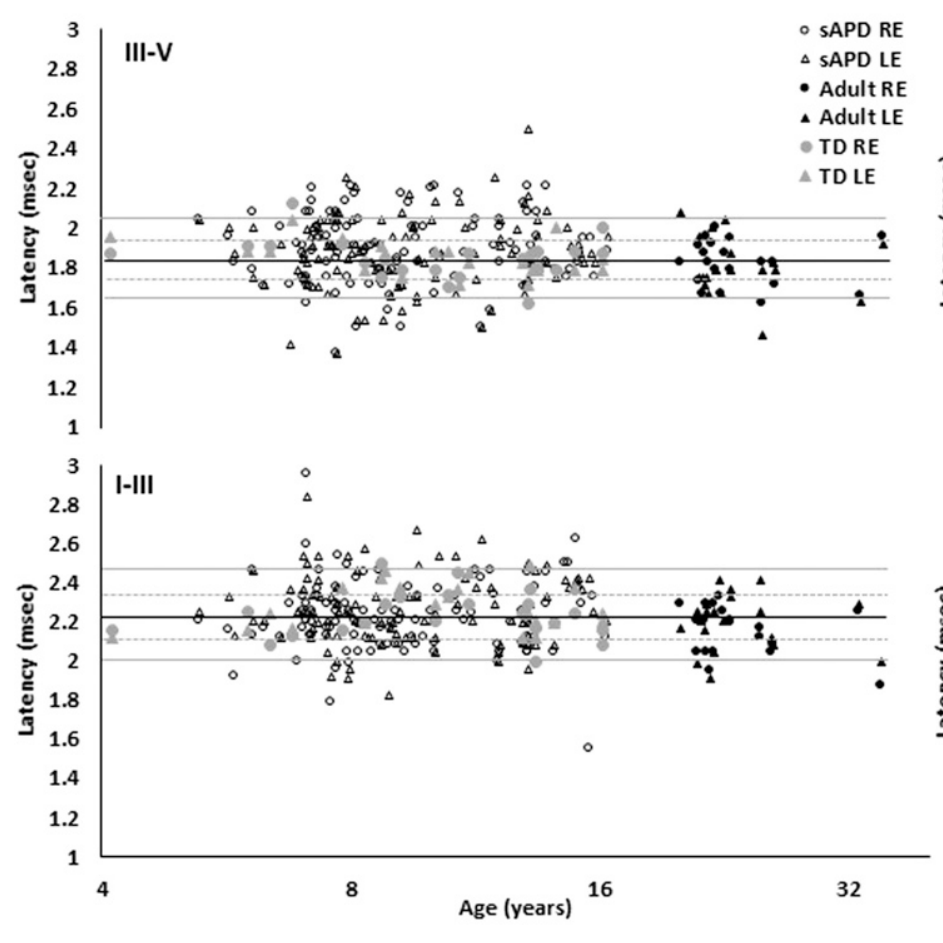

B

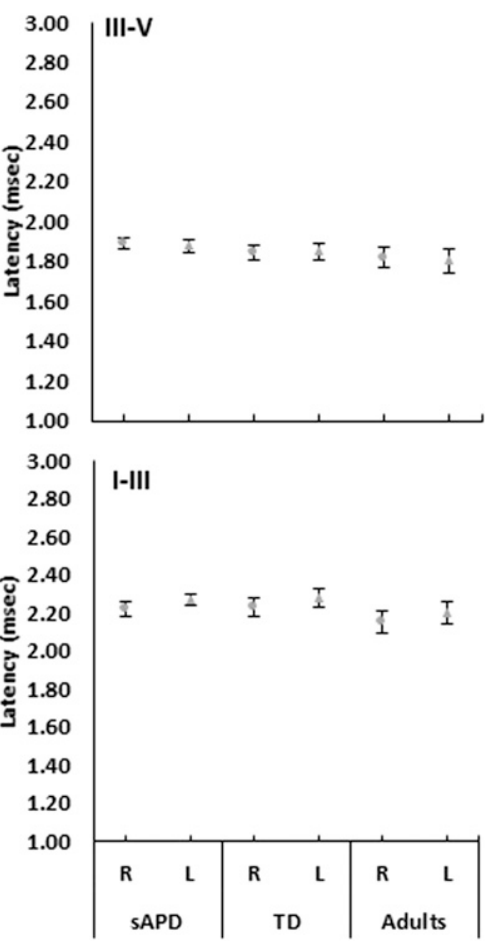

Figure 3. (A) ABR interwave intervals I-III and III-V plotted as a function of age for slow rates ( 13.3 clicks/sec). Data for TD children are shown as filled circles and filled triangles (in gray) for the right and left ears, respectively. The sAPD children responses are shown by the unfilled circles and triangles for the right and left ears, respectively. Adult responses are shown as filled circles and filled triangles (in black) for the right and left ears, respectively. The filled horizontal black line, and unfilled and filled gray lines represent TD children's mean interval latencies, \pm 1 and $\pm 2 \mathrm{SD}$, respectively. (B) Mean ABR interwave intervals I-III and III-V are plotted as a function of group for the right and left ears. Data for the right and left ears are shown as filled circles and triangles, respectively. Error bars around the mean represent $95 \%$ confidence intervals.

factor. The analysis revealed a significant difference between groups $\left[F_{(2,147)}=4.02, p=0.020,{ }^{{ }^{2}}{ }_{\mathrm{p}}=0.052\right]$, but the interwave interval by group interaction was not significant $\left[F_{(1,147)}=0.403, p=0.669,{ }^{n 2}{ }_{p}=0.005\right]$. Bonferroni post hoc tests revealed a significant group difference between adults and children sAPD $\left[t_{(147)}=\right.$ $2.91, p=0.015]$, but there were no significant differences between TD children and adults $\left[t_{(147)}=1.88\right.$, $p=0.192]$, or between TD children and children sAPD $\left[t_{(147)}=0.5, p=1.000\right]$.

Interwave intervals showed significant differences between ears $\left[F_{(1,147)}=5.80, p=0.017,{ }^{\eta 2}{ }_{\mathrm{p}}=0.038\right]$, and the ear by latency interaction was significant $\left[F_{(1,147)}=5.153, p=0.025,{ }^{n 2} \mathrm{p}=0.038\right]$. Bonferroni post hoc $t$-tests (adjusted) revealed significant ear differences in the I-III interwave interval $\left[t_{(147)}=3.21, p=0.002\right]$ but not in the III-V interwave interval $\left[t_{(147)}=0.64\right.$, $p=0.528]$.

The mean interwave intervals were elevated for sAPD children, with several sAPD children showing interwave latencies $>2$ SD beyond expectations from the TD children's data. Forty sAPD children (37.03\%) demonstrated abnormal interwave intervals (either I-III or III-V). Of these children, 28 (25.92\%) children were unilateral and $12(11.11 \%)$ were bilateral. The incidence of abnormalities in the I-III interval [ $\mathrm{n}=16$ $(14.81 \%)]$ was similar to that in the III-V $[\mathrm{n}=24$ (22.22\%)] interval. One TD child showed a I-III interval prolongation $>2$ SD. One TD child and one adult showed a III-V interval $>2$ SD. Chi-square test (two-tailed) revealed that incidence of clinically abnormal interwave intervals was significantly higher in children sAPD when compared with TD children $\left[\chi^{2}(1)=\right.$ 8.93, $p=0.003]$.

\section{Stimulus Rate Effects}

In Figure 4A, wave $\mathrm{V}$ rate change with increasing stimulation rate is plotted as a function of wave $\mathrm{V}$ slow rate latencies for TD children, SAPD children, and adults. Figure $4 \mathrm{~B}$ shows the mean rate change for wave V latency as a function of group for right and left ears. A RMANOVA was carried out with ear as a within-subject factor and subject group (TD children, sAPD children, and adults) as a between-subject factor. The wave $\mathrm{V}$ shift was significantly different between groups $\left[F_{(2,147)}=3.703, p=0.027,{ }^{\eta}{ }_{\mathrm{p}}=0.048\right]$. Bonferroni post hoc analysis showed no significant difference 
A

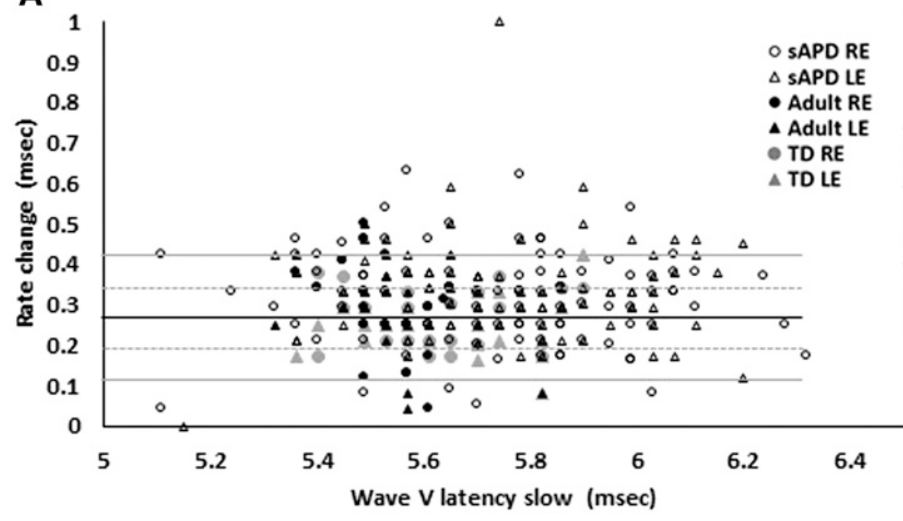

B

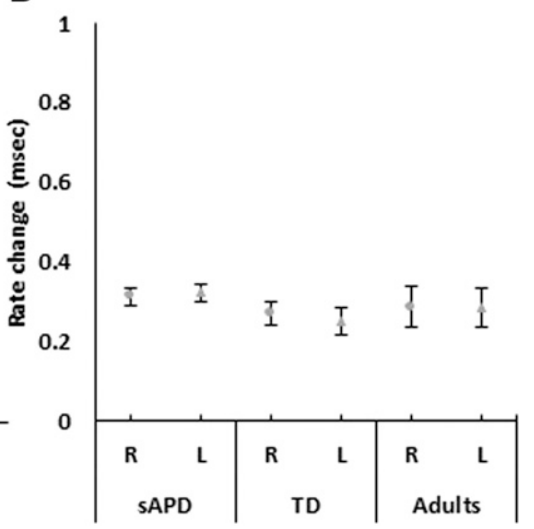

Figure 4. (A) Individual wave V rate change (57.7-13.3 clicks/sec) plotted as a function of wave V slow rate latencies (13.3 clicks/sec). Data for TD children are shown as filled circles and filled triangles (in gray) for the right and left ears, respectively. The sAPD children responses are shown by the unfilled circles and triangles for the right and left ears, respectively. Adult responses are shown as filled circles and filled triangles (in black) for the right and left ears, respectively. The filled horizontal black line, and unfilled and filled gray lines represent TD children's mean rate change, \pm 1 and $\pm 2 \mathrm{SD}$, respectively. (B) Mean wave rate change is plotted as a function of groups for the right and left ears. Data for the right and left ears are shown as filled circles and triangles, respectively. Error bars around the mean represent $95 \%$ confidence intervals.

between TD children and adults $\left[t_{(147)}=0.86, p=1.000\right]$, or between adults and children $\operatorname{sAPD}\left[t_{(147)}=1.36, p=\right.$ 0.557]. There was a significant difference between TD children and children sAPD $\left[t_{(147)}=2.50, p=0.035\right]$. There was no significant difference between ears $\left[F_{(1,147)}=0.075, p=0.782,{ }^{\eta 2} \mathrm{p}=0.001\right]$. At an individual level, 32 of the 108 clinical children $(29.62 \%)$ showed a greater than expected shift in wave $\mathrm{V}$ latency ( $>2$ SD of TD children data, $\geq 0.41 \mathrm{msec}$ ) when the stimulation rate changed from slow to fast. Of these, 24 were unilateral and 8 were bilateral. Only $18(16.66 \%)$ had shown clinically abnormal wave V absolute latencies at the slow rate.

\section{Summary}

Both group and individual data suggest that many of the children in this clinically referred group showed objective indicators of reduced neural integrity that could contribute to their reported listening difficulties. Evaluation of responses according to the model proposed by Ponton et al (1996) was used to understand the axonal conduction and synaptic contribution to abnormalities in the children's data.

\section{Evaluation of Axonal Conduction and Synaptic Transmission}

Figure 5 shows I-II, II-III, III-IV, and IV-V interwave intervals at slow (leftmost panel) and faster (rightmost panel) stimulation rates, plotted as a function of age. Figure 5 shows mean I-II, II-III, III-IV, and IV-V interwave intervals at slow and faster stimulation rates. A repeated measures analysis of variance was applied to the interwave intervals with ear (right and left), interwave interval (I-II, II-III, III-IV, and IV-V), and stimulation rate (slow and fast) as within-subject factors and group (TD children, sAPD children, and adults) as a between-subject factor. There were statistically significant differences between groups $\left[F_{(1,64)}=14.45, p<0.0001,{ }^{\eta 2}{ }_{p}=0.311\right]$ and a significant interaction between interwave interval and groups $\left[F_{(6,192)}=4.64, p<0.001,{ }^{\eta 2}{ }_{\mathrm{p}}=0.127\right]$. Bonferroni post hoc $t$-tests (adjusted) revealed no significant group differences in intervals measuring predominantly axonal conduction time (I-II: TD children versus adults $\left[t_{(64)}=0.65, p=1.000\right]$, sAPD children versus TD children $\left[t_{(64)}=0.76, p=1.000\right]$, and SAPD children versus adults $\left[t_{(64)}=0.03, p=1.000\right]$; and III-IV: TD children versus adults $\left[t_{(64)}=0.20, p=1.000\right]$, sAPD children versus TD $\left[t_{(64)}=0.69, p=1.000\right]$, and sAPD children versus adults $\left.\left[t_{(64)}=0.47, p=1.000\right]\right\}$. The II-III interval that measures synaptic transmission time did not show a significant difference when comparing TD children with adults $\left[t_{(64)}=2.17, p=0.096\right]$ or between sAPD children and TD children $\left[t_{(64)}=0.62, p=1.000\right]$. However, sAPD children did show significantly prolonged $\left[t_{(64)}=3.43, p=0.004\right]$ intervals when compared with adults. The IV-V interval was significantly prolonged in sAPD children when compared with TD children $\left[t_{(64)}=3.76, p=0.001\right]$ and adults $\left[t_{(64)}=4.91, p<\right.$ $0.001]$. There were significant differences between ears $\left[F_{(1,64)}=7.162, p=0.009,{ }^{n}{ }_{\mathrm{p}}=0.101\right]$, with the right-ear responses tending to be faster than those in the left ear. The ear by group $\left[F_{(2,64)}=0.735, p=\right.$ $\left.0.483,{ }^{2}{ }_{\mathrm{p}}=0.022\right]$ and ear by interwave interactions were not significant $\left[F_{(2.11,135.20)}=0.520, p=\right.$ $\left.0.605,{ }^{\eta 2}{ }_{p}=0.008\right]$. 

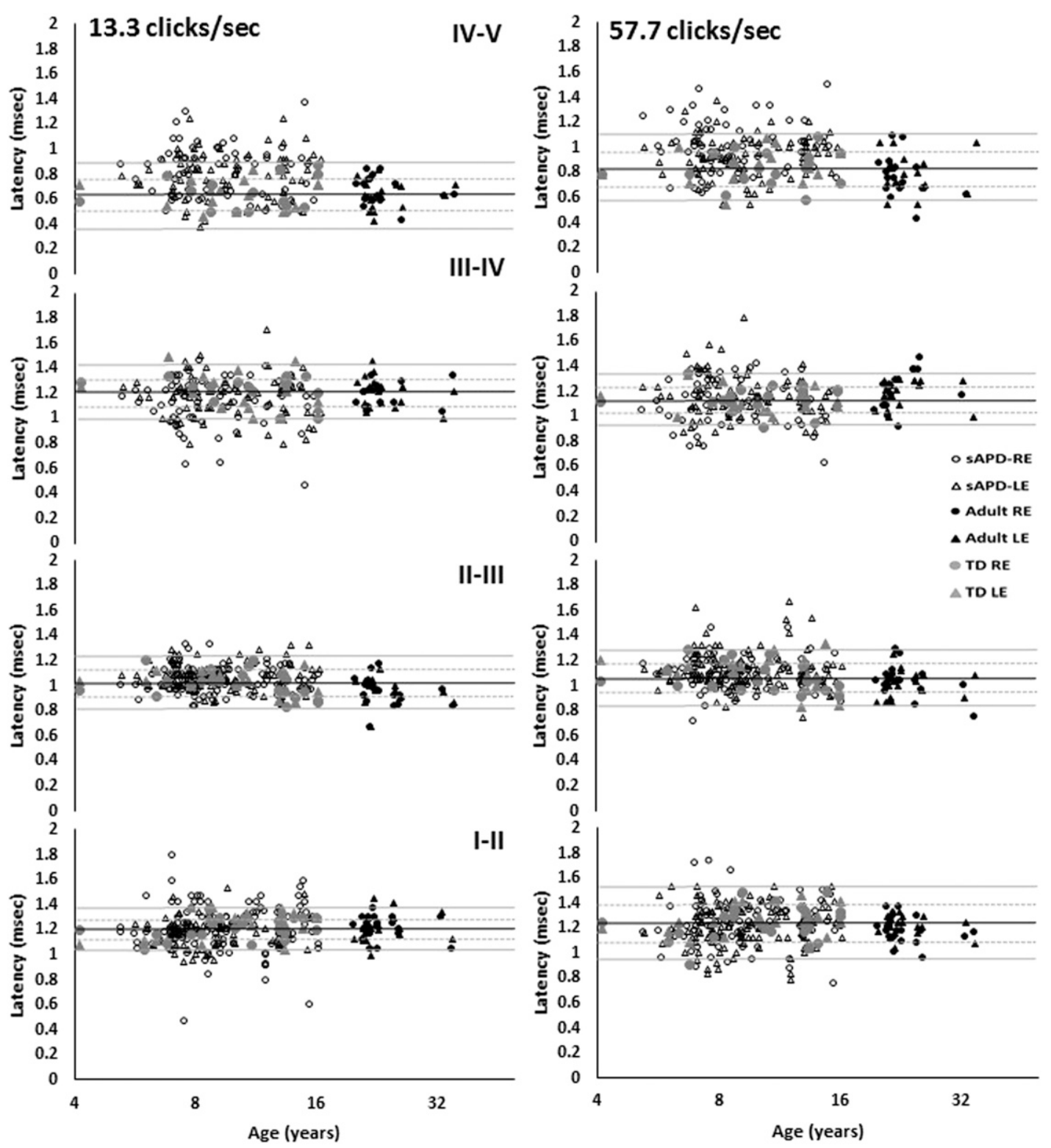

Figure 5. ABR interwave latencies I-II, II-III, III-IV, and IV-V plotted as a function of age for slow and fast rates in the left and right panels, respectively. Data for TD children are shown as filled circles and filled triangles (in gray) for the right and left ears, respectively. The sAPD children responses are shown by the unfilled circles and triangles for the right and left ears, respectively. Adult responses are shown as filled circles and filled triangles (in black) for the right and left ears, respectively. The filled horizontal black line, and unfilled and filled gray lines represent TD children mean interval latencies, \pm 1 and $\pm 2 \mathrm{SD}$, respectively.

It is clear from Figures 5 and 6 that at faster stimulation rates, interwave intervals that represent synaptic transmission showed a significant group-related change in latency when compared with interwave intervals that represent axonal conduction time. The interaction between rate and interwave interval showed a significant rate-dependant prolongation $\left[F_{(2.00,128.10)}=\right.$ $\left.36.50, p<0.001,{ }^{\eta 2}{ }_{\mathrm{p}}=0.363\right]$. Bonferroni post hoc $t$-tests (adjusted) showed that increasing the stimulation rate significantly prolonged interwave intervals that measure primarily synaptic transmission \{II-III $\left[t_{(64)}=4.54, p<0.0001\right]$ and IV-V $\left[t_{(64)}=10.55\right.$, $p<0.0001]\}$. The stimulation rate had no effect on intervals measuring axonal conduction time $\left\{\right.$ I-II $\left[t_{(64)}=\right.$ $0.72, p=0.498]\}$, but III-IV $\left[t_{(64)}=2.37, p=0.026\right]$ showed significant reduction in the interwave interval at faster stimulation rates. The three-way interaction (interpeak interval by rate by groups) was not significant $\left[F_{(6,192)}=1.26, p=0.276,{ }^{n 2} \mathrm{p}=0.038\right]$. Figure 7 shows the grand average waveforms (13.3 clicks/sec) for TD children and adults, with some sample waveforms for individual sAPD children with clinically abnormal $(>2$ SD expectation from TD children) axonal or synaptic prolongation. 


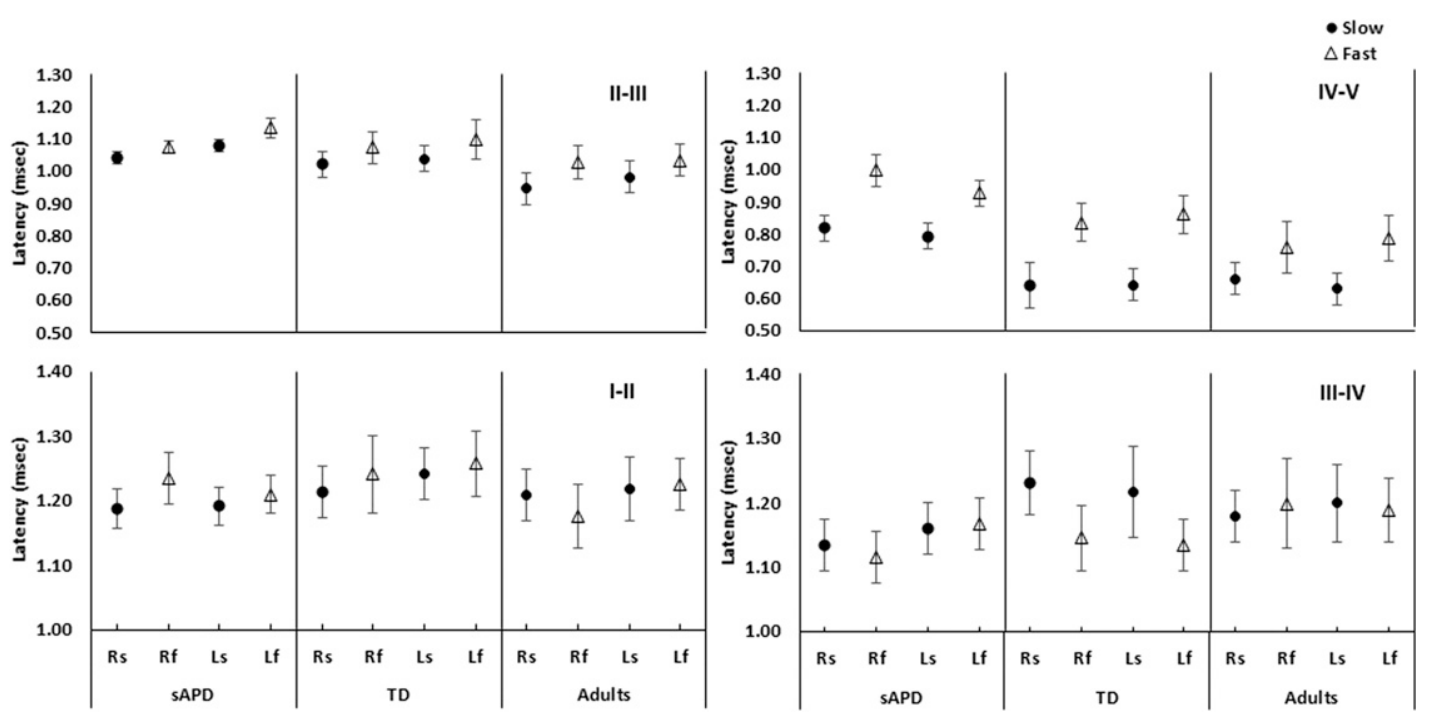

Figure 6. Mean interpeak intervals plotted for the right ear slow (Rs), right ear fast (Rf), left ear slow (Ls), and left ear fast (Lf) for children sAPD, TD children, and adults. Graphs in the top panel show mean latencies for interpeak intervals that represent synaptic transmission and graphs in the bottom panel show mean latencies that represent axonal conduction times. In each graph, slow and fast rate mean data are shown in filled circles and unfilled triangles, respectively. Error bars around the mean represent $95 \%$ confidence intervals.

The intra-subject stability (or repeatability) of the ABR was examined. The ABR stability was measured by calculating the Pearson product moment correlation coefficient $(r)$ between two subaverage waveforms (2,000 trials each), using the correlation function in the Bio-logic Navigator Pro. The Pearson correlation value varies from 0 to 1 . Lower $r$ values represent a more variable response across trials, whereas higher $r$ values represent more stable (i.e., more consistent) responses. The stability of ABR recorded at both slow (13.3 clicks/sec) and faster stimulation rates (57.7 clicks/sec) was analyzed between 0 and $8 \mathrm{msec}$. A similar approach has been used by other researchers to examine the neural response stability in normal children and children with speech and language disorder (Lam et al, 2017; Otto-Meyer et al, 2018; Tichko and Skoe, 2018).

Figure 8 shows the mean change in response stability in $r$ values as a function of the click stimulus rate for sAPD children, TD children, and adults. The average correlational values were higher for $\mathrm{ABR}$ recorded at slow stimulation rates $(13.3$ clicks/sec) than for that at faster stimulation rates ( 57.7 clicks $/ \mathrm{sec})$. The average correlation values of SAPD were lower than those of TD children and adults. Before statistical analysis, $r$ values were Fisher-transformed. A RMANOVA was completed with ear (right and left) and stimulation rates (13.3 and 57.7 clicks/sec) as within-subject factors and subject group as a between-subject factor (sAPD children, TD children, and adults). There was a significant difference between groups $\left[F_{(2,147)}=5.08, p=0.007,{ }^{{ }^{2}}{ }_{\mathrm{p}}=0.065\right]$. At slower stimulation rates (13.3 clicks/sec), all three groups showed better stability of ABR waveforms than faster stimulation rates $(57.7$ clicks/sec $)\left[F_{(1,}, 147\right)=$ $19.86, p<0.001,{ }^{\mathrm{n} 2} \mathrm{p}=0.11$, but the rate by group interaction was not significant $\left[F_{(2,147)}=0.82, p=0.921\right.$, $\left.{ }^{{ }^{2} 2}{ }_{\mathrm{p}}=0.001\right]$. Bonferroni post hoc $t$-tests (adjusted) showed that children suspected with APD had less stable ABR waveforms than TD children $\left[t_{(147)}=2.54, p=\right.$ 0.039]. Other group differences were not significant [adults and children sAPD, $t_{(147)}=2.34, p=0.061$; TD children and adults, $\left.t_{(147)}=0.59, p=1.000\right]$. There were no significant differences between ears $\left[F_{(1,147)}=\right.$ $\left.1.61, p=0.20,{ }^{\mathrm{n} 2} \mathrm{p}=0.011\right]$, and other interactions were not significant $(p>0.05)$.

\section{DISCUSSION}

$\mathrm{P}$ rofessional guidelines (ASHA, 2005) argue that a disorder in auditory processing should be attributable to a deficit in the neural processing of auditory stimuli that lies beyond simple sound detection and not to deficits in cognitive or language-related functions. The use of speech-based tests during assessment, often with complex instructions, makes it difficult to rule out the contribution of these higher order processes. Although the ABR may be a useful tool for exploring the integrity of the auditory brainstem pathways without potential confounds, it is not widely used for APD assessment (Emanuel et al, 2011), largely because of a lack of supporting evidence (Katz et al, 2000; AAA, 2010). This study was aimed at exploring ABRs recorded in clinically referred children who presented with reporting listening difficulties using standard clinical measures (absolute latencies, interwave intervals, and effect of stimulus rate on wave $\mathrm{V}$ latency) and a 


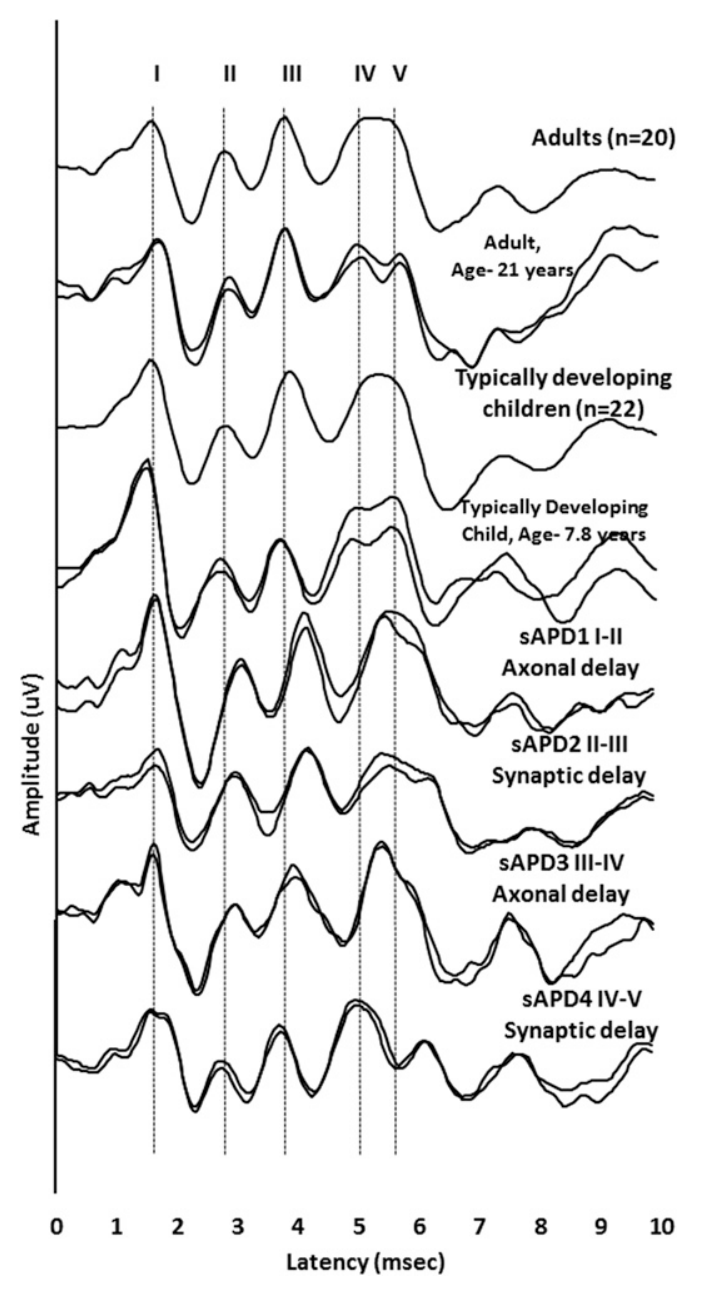

Figure 7. Auditory brainstem response waveforms recorded at $13.3 \mathrm{click} / \mathrm{sec}$ are shown for adult participants (grand average), an individual adult, TD children (grand average), an individual TD child, and for individual children SAPD with clinically abnormal ( $>2$ SD of TD children expectation) axonal or synaptic prolongation. Compared with adults and TD children, individual children sAPD showed significant delays in interpeak intervals that represent axonal (SAPD1, I-II interpeak interval; and sAPD3, III-IV interpeak interval) and synaptic transmission time (sAPD2, II-III interpeak interval; and sAPD4, IV-V interpeak interval).

more detailed analysis that attempts to separate, as much as possible, axonal and synaptic factors contributing to brainstem transmission (Ponton et al, 1996).

The ABR relies on faithful transmission of rapidly occurring acoustic stimuli across and between axons and synapses. The auditory synapses are specialized for reliable transmission at fast stimulation rates (Fuchs, 2005), and axonal myelination ensures rapid travel between synapses. Developmentally, it has been observed that ABRs recorded from infants and very young children have shown prolonged latencies at slower stimulation rates and greater shifts in latency at faster stimulation rates when compared with adults. These differences can be attributable to axonal transmission changes due to incomplete myelination and reduced synaptic efficiency (Jiang et al, 1991; Lasky, 1997), both of which show strong maturational changes during the first few years of life (Moore and Linthicum, 2007; Kral and Sharma, 2012).

This study showed ABR abnormalities in many of the children seen for clinical evaluation of listening difficulties, consistent with our previous study (Allen and Allan, 2014). It is likely that these observed abnormalities were not the result of normal maturation. It can be seen in Figures 2, 3, and 5 that no age effects were observed in either TD children or those with listening difficulties. Analysis also revealed no significant differences between TD children and adults. Our findings are consistent with many previously published studies, indicating that the ABR is mature before five years of age. Some recent studies examining the ABR to speech stimuli have indicated that wave $\mathrm{V}$ may show prolonged maturation ( $~ 12$ years) (Krizman et al, 2015; Skoe et al, 2015). Skoe et al (2015) showed an average wave $\mathrm{V}$ latency that is $0.2 \mathrm{msec}$ earlier for children between 8 and 11 years (most comparable in age to the children in this study) when compared with that of young adults. In this study, although some children showed early wave $\mathrm{V}$ relative to the adults, the Pearson correlation between age and the wave V absolute latencies of TD children showed no significant correlation (two-tailed) (right ear: $r=0.18, p=0.40$; left ear: $r=0.10, p=0.62$ ) and group effects were not significant.

Many of the sAPD children whose data were included in this study showed clinically abnormal ( $>2$ SD above expectation) absolute latencies and interwave intervals when compared with normal hearing TD children, occurring with similar frequency in the lower and upper brainstem pathways. The Ponton model offered additional insight into possible mechanisms underlying these findings. The incidence of clinically significant prolonged synaptic transmission in the SAPD children was higher $(\mathrm{n}=40,37.03 \%)$ than were abnormalities associated with atypical axonal conduction $(\mathrm{n}=17$, 15.74\%) (see Figure 7 for sample waveforms). Very few $(\mathrm{n}=4,3.70 \%)$ showed both. Synaptic function in the auditory nerve itself is not assessed unless the absolute latency of wave I is examined. As can be seen in the lowermost panel of Figure 2, wave I latency was prolonged or shortened in the data from many individual sAPD children. Given that all sAPD children had normal middle ear function, this delay in wave $I$ is most likely attributable to deficiencies that may very well arise in the first auditory synapse, suggesting a peripheral origin of the listening difficulties observed in some children referred for auditory processing assessment. This reinforces the need for including electrophysiology measures in the auditory processing assessment battery. 


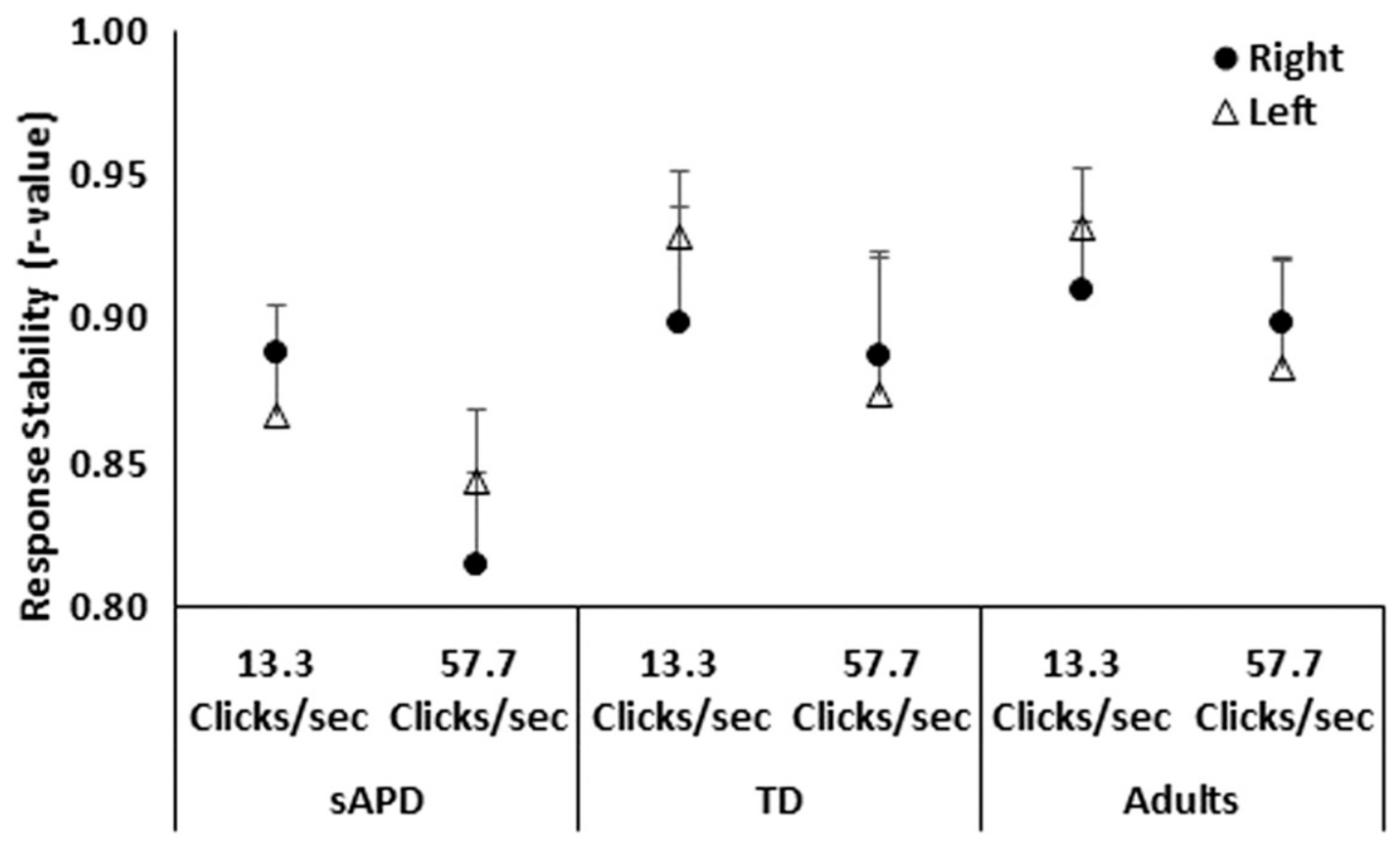

Figure 8. Mean change in ABR stability in $r$ values as a function of the click rate (13.3 and 57.7 clicks/sec) for sAPD children, TD children, and adults. Error bars around the mean represent $95 \%$ confidence intervals.

The model proposed by Ponton et al (1996) is not the only attempt to define the possible generators of the ABR. Melcher et al (1996a,b) and Melcher and Kiang (1996) also investigated the ABR generators, but in cats. They demonstrated that a lesion within the CNC led to an ABR with reduced amplitude and prolonged latencies measurable throughout the response. Both models agree that wave I (or cat P1) is generated from the spiral ganglion. Melcher et al (1996b) and Melcher and Kiang (1996) showed that the cat P2 (human wave II) is generated by the globular cells in the CNC; hence, the cat P1-P2 interval (human I-II interval) may have axonal and synaptic components. The Ponton model proposes that wave II is generated from the proximal end of the auditory nerve (as it enters the brainstem) and proposed that the I-II interval is largely axonal. Similar to the Ponton model, other investigators believe that the I-II interval is largely determined by the axonal/ auditory nerve conduction, based on intra-surgical recordings in humans (Møller and Jannetta, 1982) and abnormal I-II prolongations in individuals with confirmed $8^{\text {th }}$-nerve tumors (Møller and Moller, 1983). The findings of the present study demonstrated no significant differences in auditory nerve conduction between groups, although several individuals showed differences. There were no maturational trends in the children's data. At faster stimulation rates, no significant differences in auditory nerve conduction time were found between the three groups. This finding suggests that the rate has a minimal effect on axonal conduction. Similar findings have been reported in the literature (Pratt et al, 1981), and it can be speculated that Pon- ton's assumption about the I-II interval in the human is reasonable.

The Ponton model indicated that human wave III is generated by fibers that are exiting from the CNC. Similar findings were observed by Melcher et al (1996b) and Melcher and Kiang (1996). Ponton proposed that the II-III delay may contain axonal and synaptic delay $(>50 \%)$ and the maturation may be prolonged because of developmental changes in the brainstem circumference. Previous studies have reported that adult II-III intervals range from $0.91 \mathrm{msec}$ (Salamy and McKean, 1976) to $1.12 \mathrm{msec}$ (Jiang et al, 1991). The II-III interval of adults from this study $(0.94 \mathrm{msec})$ closely matches with those published values. In this study, adults and TD children did not show significant differences in the II-III interval, but in sAPD children, the II-III interval was significantly prolonged when compared with adults. These findings suggest that the delays in SAPD children may be more likely to arise from a synaptic type of abnormality in the lower brainstem.

Ponton, Melcher et al (1996b), and Melcher and Kiang (1996) agree that wave IV (cat P4) is generated from the MSO principal cells (contralateral side). Ponton proposed that the III-IV interval is dominated by the axonal conduction based on the path segment lengths measured from the ipsilateral CNC to the contralateral MSO. The Ponton model stated that the estimated axonal conduction velocity for III-IV and I-II was similar in adults. Based on this, they concluded that the III-IV interval is dominated by axonal conduction. In this study, all three groups of participants demonstrated similar conduction times in the III-IV interval. 
Melcher et al (1996b) and Melcher and Kiang (1996) assume that the P5 (human wave V) is generated from the cell bodies in the LL or IC. They also argue that the P4 and P5 are generated by serially connected cells with axonal and synaptic delays. The estimated transmission delay between P4 and P5 was approximately 1.1-1.6 msec. The Ponton model assumes that wave $\mathrm{V}$ is generated from the LL. They hypothesized that the IV-V interval is dominated by the synaptic transmission and the maturation is prolonged when compared with the III-IV interval. The estimated transmission delay between wave IV and V was approximately 0.6 to $0.7 \mathrm{msec}$. The TD children and adults in the present study demonstrated IV-V interval of $\sim 0.64$ msec and $\sim 0.63 \mathrm{msec}$, respectively. When compared with the Melcher et al (1996b) and Melcher and Kiang (1996) estimation of IV-V transmission delay, the findings of the present study more closely match with that of the Ponton model estimation. The current data revealed no effect of age in IV-V transmission time and the latencies of TD children were similar to those of adults. But children sAPD showed significantly prolonged IV-V transmission time when compared with age-matched TD children and adults, again suggesting a synaptic pattern of abnormality.

At a faster stimulation rate (57.7 clicks/sec), clinical analysis of rate-dependent changes in wave $\mathrm{V}$ shows delays that are predictable but age dependent and reaching adult-like values by school age (Jirsa, 2001). In this study, children sAPD showed significantly prolonged wave $\mathrm{V}$ latency at faster stimulation rates when compared with age-matched TD children. These results are consistent with previous studies that showed abnormal wave $\mathrm{V}$ latency shift as a result of the increase in temporal stress (Jirsa, 2001; Allen and Allan, 2014). It has been suggested that a faster stimulation rate may have a greater effect on synaptic transmission than on axonal conduction (Pratt et al, 1981). Detailed analysis showed that the II-III and IV-V intervals for all three groups were increased when the stimulus rate increased, consistent with synaptic influences. However, interwave intervals that represent axonal conduction showed a different effect of the stimulus rate. The I-II interwave interval did not show any change but the III-IV interwave interval showed decreased transmission time.

Ear differences in interwave intervals have been reported in the literature. The significantly shorter interwave intervals in the right ear compared with those in the left ear have been reported in large cohorts of healthy neonates (Sininger and Cone-Wesson, 2006; Coenraad et al, 2010) and in children with speech and language disorders (Roth et al, 2012). All three groups in our study demonstrated shorter interwave latencies in the right ear than in the left ear. These results may support a right-ear advantage in the lower levels of the auditory system.

Presently, the precise cause for APD is unknown. The literature does suggest that environmental factors (e.g., otitis media and hyperbilirubinemia) during the critical periods of auditory development may influence APD (Greville, 1990; Hall and Grose, 1993; Maruthy and Mannarukrishnaiah, 2008; Amin et al, 2014). A reported group of children around seven years of age who had experienced high levels of bilirubin (jaundice) showed no group differences in ABRs (absolute, interwave latencies, and amplitudes) when compared with age-matched controls, but some of the individual children with a history of jaundice did show abnormal wave $\mathrm{V}$ morphology when compared with age-matched controls (Greville, 1990). Similarly, children with a history of otitis media have shown abnormal ABR characterized by prolonged absolute (Hall and Grose, 1993) and interwave latencies (Hall and Grose, 1993; Maruthy and Mannarukrishnaiah, 2008). Thus, observed ABR abnormalities in the present study may have been influenced by these environmental factors.

Animal models may provide some additional insight into potential APD causal factors. Mouse models of mutant genes that affect axonal conduction (KoppScheinpflug et al, 2003; Middlebrooks et al, 2013) or synaptic transmission (Satheesh et al, 2012; Pirone et al, 2014) have shown evidence of impaired auditory processing that may be related to underlying abnormalities in cellular mechanisms that could theoretically contribute to abnormal ABRs such as those observed in this study.

The use of the Ponton model suggested that most ABR abnormalities observed in children with APD are likely to arise from synaptic rather than axonal factors, often originating at the very first synapse. Although hearing thresholds fell within normal limits, between-group differences further support a deficiency that may be peripheral in origin. The Ponton model is silent with regard to contributions from factors before the first synapse. A delay in synaptic transmission or poor neural stability in the lower level of the auditory system may affect the encoding of sound at higher levels in the auditory system. These deficits may only be visible when neurophysiologic measures are included in clinical assessment.

Acknowledgments. The authors would like to thank all the participants, and their families, who participated in this study.

\section{REFERENCES}

Allen P, Allan C. (2014) Auditory processing disorders: relationship to cognitive processes and underlying auditory neural integrity. Int J Pediatr Otorhinolaryngol 78:198-208.

American Academy of Audiology (AAA). (2010) Diagnosis, treatment, and management of children and adults with central auditory processing disorder. www.audiology.org. Accessed March 20, 2016. 
American Speech-Language-Hearing Association (ASHA). (2005) (Central) auditory processing disorders [Technical Report]. www. asha.org/policy. Accessed March 20, 2016.

Amin S, Orlando M, Monczynski C, Tillery K. (2014) Central auditory processing disorder profile in premature and term infants. Am J Perinatol 32:399-404.

Anderson K. (1989) Screening Instrument for Targeting Educational Risk (SIFTER) in Children with Identified Hearing Loss. Tampa, FL: Educational Audiology Association.

Carhart R, Jerger JF. (1959) Preferred method for clinical determination of pure-tone thresholds. $J$ Speech Hear Disord 24: 96-108.

Chermak GD, Musiek FE. (1997) Central Auditory Processing: New Perspectives. San Diego: Singular Publishing Group Inc.

Coenraad S, van Immerzeel T, Hoeve LJ, Goedegebure A. (2010) Fitting model of ABR age dependency in a clinical population of normal hearing children. Eur Arch Otorhinolaryngol 267: 1531-1537.

Dawes P, Bishop D. (2009) Auditory processing disorder in relation to developmental disorders of language, communication and attention: a review and critique. Int J Lang Commun Disord 44:440-465.

Eggermont JJ, Salamy A. (1988) Maturational time course for the $\mathrm{ABR}$ in preterm and full term infants. Hear Res 33:35-47.

Emanuel DC, Ficca KN, Korczak P. (2011) Survey of the diagnosis and management of auditory processing disorder. Am J Audiol 20: $48-60$.

Fuchs PA. (2005) Time and intensity coding at the hair cell's ribbon synapse. $J$ Physiol 566:7-12.

Gopal KV, Kowalski J. (1999) Slope analysis of Auditory Brainstem Responses in children at risk of central auditory processing disorders. Scand Audiol 28:85-90.

Gorga MP, Kaminski JR, Beauchaine KL, Jesteadt W, Neely ST. (1989) Auditory brainstem responses from children three months to three years of age: normal patterns of response. II. $J$ Speech Hear Res 32:281-288.

Greville KA. (1990) Central auditory processing in children with a history of neonatal jaundice. DissertationUniversity of Auckland.

Hall JW. (2006) New Handbook for Auditory Evoked Responses. Boston: Allyn \& Bacon.

Hall JW. (2007) Moving toward evidence-based diagnosis and management of APD in children. Hear $J$ 60:10-14.

Hall JW, Grose JH. (1993) The effect of otitis media with effusion on the masking-level difference and the auditory brainstem response. J Speech Lang Hear Res 36:210.

Hecox K, Galambos R. (1974) Brain stem auditory evoked responses in human infants and adults. Arch Otolaryngol 99:30-33.

Hind S. (2006) Survey of care pathway for auditory processing disorder. Audiol Med 4:12-24.

Jiang ZD, Zheng MS, Sun DK, Liu XY. (1991) Brainstem auditory evoked responses from birth to adulthood: normative data of latency and interval. Hear Res 54:67-74.
Jiang ZD, Zhang L, Wu YY. (1993) Brainstem auditory evoked responses from birth to adulthood: development of wave amplitude. Hear Res 68:35-41.

Jirsa RE. (2001) Maximum length sequences-auditory brainstem responses from children with auditory processing disorders. $J$ Am Acad Audiol 12:155-164.

Katz J, Johnson CD, Brandner S, Delagraange T, Ferre J, King J, Kossover-Wechter D, Lucker J, Medwetsky L, Saul R, Rosenberg GG, Stecker N, Tillery K. (2000) Clinical and research concerns regarding the 2000 APD consensus report and recommendations. Audiol Tod 14:14-17.

Kopp-Scheinpflug C, Fuchs K, Lippe WR, Tempel BL, Rubsamen R. (2003) Decreased temporal precision of auditory signaling in Kcna1-null mice: an electrophysiological study in vivo. $J$ Neurosci 23:9199-9207.

Kral A, Sharma A. (2012) Developmental neuroplasticity after cochlear implantation. Trends Neurosci 35:111-122.

Krizman J, Tierney A, Fitzroy AB, Skoe E, Amar J, Kraus N. (2015) Continued maturation of auditory brainstem function during adolescence: a longitudinal approach. Clin Neurophysiol 126: $2348-2355$.

Lam SS, White-Schwoch T, Zecker SG, Hornickel J, Kraus N. (2017) Neural stability: a reflection of automatic reading. Neuropsychologia 103:167.

Lasky RE. (1997) Rate and adaptation effects on the auditory evoked brainstem response in human newborns and adults. Hear Res 111:165-176.

Lauter JL, Loomis RL. (1986) Individual differences in auditory electric responses: comparisons of between-subject and withinsubject variability. I. Absolute latencies of brainstem vertex-positive peaks. Scand Audiol 15:167-172.

Maruthy S, Mannarukrishnaiah J. (2008) Effect of early onset otitis media on brainstem and cortical auditory processing. Behav Brain Funct 4:17.

Melcher JR, Knudson IM, Fullerton BC, Guinan JJ, Norris BE, Kiang NY. (1996a) Generators of the brainstem auditory evoked potential in cat. I. An experimental approach to their identification. Hear Res 93:1-27.

Melcher JR, Kiang NY. (1996) Generators of the brainstem auditory evoked potential in cat. III: identified cell populations. Hear Res 93:52-71.

Melcher JR, Guinan JJ, Knudson IM, Kiang NY. (1996b) Generators of the brainstem auditory evoked potential in cat. II. Correlating lesion sites with waveform changes. Hear Res 93: $28-51$.

Middlebrooks JC, Nick HS, Subramony SH, Advincula J, Rosales RL, Lee LV, Ashizawa T, Waters MF. (2013) Mutation in the Kv3.3 voltage-gated potassium channel causing spinocerebellar ataxia 13 disrupts sound-localization mechanisms. PLoS One 8:e76749.

Mochizuki Y, Go T, Ohkubo H, Tatara T, Motomura T. (1982) Developmental changes of brainstem auditory evoked potentials (BAEPs) in normal human subjects from infants to young adults. Brain Dev 4:127-136.

Møller AR, Jannetta PJ. (1982) Auditory evoked potentials recorded intracranially from the brain stem in man. Exp Neurol 78:144-157. 
Møller MB, Møller AR. (1983) Brainstem auditory evoked potentials in patients with cerebellopontine angle tumors. Ann Otol Rhinol Laryngol 92:645-650.

Moore JK, Linthicum FH. (2007) The human auditory system: a timeline of development. Int J Audiol 46:460-478.

Otto-Meyer S, Krizman J, White-Schwoch T, Kraus N. (2018) Children and autism spectrum disorder have unstable neural responses to sound. Exp Brain Res 236:733-743.

Pirone A, Kurt S, Zuccotti A, Ruttiger L, Pilz P, Brown DH, Franz C, Schweizer M, Rust MB, Rubsamen R, Friauf E, Knipper M, Engel J. (2014) $\alpha 2 \delta 3$ is essential for normal structure and function of auditory nerve synapses and is a novel candidate for auditory processing disorders. J Neurosci 34:434-445.

Ponton CW, Moore JK, Eggermont JJ. (1996) Auditory brain stem response generation by parallel pathways: differential maturation of axonal conduction time and synaptic transmission. Ear Hear 17: $402-410$.

Pratt H, Ben-David Y, Peled R, Podoshin L, Scharf B. (1981) Auditory brain stem evoked potentials: clinical promise of increasing stimulus rate. Electroencephalogr Clin Neurophysiol 51:80-90.

Roth DAE, Muchnik C, Shabtai E, Hildesheimer M, henkin Y. (2012) Evidence for atypical auditory brainstem responses in young children with suspected autism spectrum disorders. Dev Med Child Neurol 54:23-29.

Salamy A, McKean CM. (1976) Postnatal development of human brainstem potentials during the first year of life. Electroencephalogr Clin Neurophysiol 40:418-426.
Salamy A. (1984) Maturation of the auditory brainstem response from birth through early childhood. J Clin Neurophysiol 1: 293-329.

Satheesh SV, Kunert K, Rüttiger L, Zuccotti A, Friauf E, Knipper M, Bartsch D, Nothwang HG. (2012) Retrocochlear function of the peripheral deafness gene Cacna1d. Hum Mol Genet 21: 3896-3909.

Sharma M, Purdy SC, Kelly AS. (2009) Comorbidity of auditory processing, language, and reading disorders. J Speech Lang Hear Res 52:706-722.

Sininger YS, Cone-Wesson B. (2006) Lateral asymmetry in the ABR of neonates: evidence and mechanisms. Hear Res 212:203-211.

Skoe E, Krizman J, Anderson S, Kraus N. (2015) Stability and plasticity of auditory brainstem function across the lifespan. Cereb Cortex 25:1415-1426.

Smoski WJ, Brunt MA, Tannahill JC. (1998) Children's Auditory Performance Scale. Tampa, FL: Educational Audiology Association.

Stapells DR, Oates P. (1997) Estimation of the pure-tone audiogram by the auditory brainstem response: a review. Audiol Neurootol 2:257-280.

Starr A, Achor J. (1975) Auditory brain stem responses in neurological disease. Arch Neurol 32:761-768.

Tichko P, Skoe E. (2018) Musical experience, sensoryneural auditory processing, and reasing subskills in adults. Brain Sci 8:E27. 